[To te presentedrat the 8th Conference on the Applifation of Accelerators in Research and Industry, November 12-14, 1984, Denton. Texas]

CONE $-841117--51$

DE85 007540

\title{
ACCELERATOR-BASED PLASMA-WALL INTERACTION STUDIES ON THE TEXTOR TOKAMAK
}

\author{
R. A. Zuhr
}

\author{
Bv eccaptence of this article, the \\ publisher or recipient ecknowiedge \\ the U.S. Government's picht to \\ retain e nonoxelunive, royal ty-free \\ license in and to any copyright \\ covering the erticle.
}

\author{
SOLID STATE DIVISION \\ OAK RIDGE NATIONAL LABORATORY \\ Operated by \\ MARTIN MARIETTA ENERGY SYSTEMS INC. \\ for the \\ UNITED STATES OEPARTMENT OF ENERG \\ Oak Ridge, Tennessee
}

September 1984

\section{DISCLAIMER}

This report was prepared as an account of work sponsored by an agency of the United States Government. Neither the United States Government nor any agency thereof, nor any of their employees, makes any warranty, express or implied, or assumes any legal liability or responsibility for the accuracy, completeness, or usefulness of any information, apparatus, product, or process disclosed, or represents that its use would no: infringe privately owned rights. Reference herein to any specific commercial product, process, or service by trade name, trademark, manufacturer, Gr otherwise does not necessarily constitute or imply its endorsement, recommendation, or favoring by the United States Government or any agency thereof. The views and opinions of authors expressed herein do not necessarily state or reflect those of the United States Government or any agency thereof. 
ACCELERATOR-BASED PLASMA-WALL INTERACTION STUDIES ON THE TEXTOR TOKAMAK*

\author{
R. A. Zuhr \\ Solif State Dfviston, Oak Ridge Nattonal Laboratory \\ Oak Ridge, TN 37831
}

\begin{abstract}
Deposition probes are commonly used to determine plasma edge characteristics in tokamaks. Such probes are frequently analyzed using acceleratorbased techniques and can yield information on impurity fiuxes, hydrogen fluxes and energies, and surface erosion rates in the plasma edge. Several types of deposition probes have been employed to investigate the plasma edge region oi the TEXTOR tokamak in Jülich, FRG. TEXTOR is a moderate size tokamak (major radius $=1.75 \mathrm{~m}$ ) that is capable of $2-3 \mathrm{~s}$ discharges and contains a liner that can be heated to $600^{\circ} \mathrm{C}$. These capabtlities make TEXTOR particularly attractfve for the study of plasma-wall interactions. Several countries, including the United States, Sweden and the host nation, are carrying on -rtive research programs in the area of plasma-edge studies. This research lias included measurements of plasma, impurity, and power fluxes at various radif in the scrapeoff layer. The results achfeved in characterizing the plasma edge in these recent probe studtes on TEXTOR will be revfewed.
\end{abstract}

\footnotetext{
*Research sponsored by the Office of Fusion Energy, U. S. Department of Energy under contract DE-AC05-840R21400 with Martin Marietta Energy Sysiems Inc.
} 


\section{- I. INTRODUCTION}

During the last several years the use of collection probe techniques to characterize the scrapeoff layer of magnetic confinement fusion experiments has become widespread.1 The plasma edge region of a confinement device is a difficult environment in which to make measurements, containing, as it does, both fons and neutrals of a varfety of spectes at energies ranging irom tenths of electron volts to tens of kflovolts. Complex physical and chemical processes are taking place on the walls and limiters. ${ }^{2}$ Large magnetic fields are always presert and destructivley high power levels can be encountered during disruptive behavior. Optical methods mich can be used under these conditions are often limited to observation of a single state of a single element or are dependent upon detafled modeling of local conditions to ubtain quantitative results. Deposition probes, on the other hand, are sensitive to all states $n$ " all elements and can be easily used to determine the types and quantities of impurities present in the edge. With interpretation, probe measurements are also capable of determining fluxes and energies of hydrogen isotopes. Time resolution during a discharge can be achieved by using rotating or moving collectors. Electrical blasing can be used to incorporate the features of a Langmuir probe into the system and thermocouple temperature measurements can be used to measure heat fluxes. This versatflity, along with its abflity to detect many elements simultaneously and its basic simplicity, have made the deposition probe a principal diagnostic for the plasma edge region.

After a deposition probe has been exposed in the scrapeoff layer the amounts of impurities and hydrogen isotopes retained on the samples must be determined. It is here that acceierator based analysis techniques make a significant contribution.1.3 The absolute quantities of impurity elenents on the 
surface can be measured eastly by Rutherford backscattering (RBS), normally with MeV ${ }^{4} \mathrm{He}$ ions, and the hydrogen isotopes present can be determined using nuclear reaction analysis (NRA) or elastic recoll detection (ERD). ${ }^{4}$ All of these methods have been applied on TEXTOR exposed samples.

TEXTOR is a moderate size tokamak (Major radius $=1.75 \mathrm{~m}$, minor radius = 0.5 m) at the Kernforschungsanlage (KFA) Jultch, FRG, that was designed for the testing of fuston related technologies. It incorporates two features that make it particularly interesting for the study of plasma-material interactions. First it is capable of comparatively long (2-3 s) discharges that can be used to study fmpurfty accumulation, and second, it contains a liner instde the vacuum vessel that can be heated to $600^{\circ} \mathrm{C}$ during operation. Plasma-wall interaction studies on TEXTOR are the subject of an international collaboration and to date six different collection probes, including the present one, have been employed on the tokamak.

\section{EXPERIMENTAL PROCEDURE}

Both single crystal silicon and carbon (Papyex) collection probes were exposed in the TEXTOR plasma edge using an automated insertion system that permitted remote positioning of the samples and automatic rotation during a discharge for time-resolved measurements. A schemattc diagram of the probe and fts relation to the plasma are shown in Fig. 1. The probe was kept at the floating potential for all measurements and the samples were masked by a titanfum window. No titanfum was detected on any of tha samples. All measurements were made in standard ohmic discharges having the following parameters: toroidal field $=2 T$, plasma current $=340 \mathrm{kA}$, line average electron density $=2-3 \times 10^{13}$ $\mathrm{cm}^{-3}$, central electron temperature $>1 \mathrm{keV}$, and discharge length $=2.5 \mathrm{~s}$. The 
temperature of the inconel 1 iner was $130^{\circ} \mathrm{C}$ and the stainless steel main 1 imiters were at a minor radius of $45 \mathrm{~cm}$. The probe was located on the horizontal midplane of the tokamak on the outside wall between toroidal field coils seven and eight, only one sector in the fon drift direction from the main limiters. Measurements were made as a function of time for various radial positions in both hydrogen and deuterfum plasmas.

After exposure the samples were removed and transported in air to a $2.5 \mathrm{MeV}$ Van de Graaff accelerator facility for analysis. Retained impurities were measured by RBS on both carbon and stlicon samples. The (100) single crystal silicon samples were oriented with the incident $2.0 \mathrm{MeV}{ }^{4} \mathrm{He}$ beam channeled along the $\langle 110\rangle$ axis at $45^{\circ}$ to the surface normal. The solid state detector was placed at a scattering angle of $135^{\circ}$. This geometry, with the incident beam in an axtal channeling direction, 5 reduces the backscattering from the silicon substrate and improves the signal to background ratio by a factor of 250 , permitting more rapid processing of the samples. Oxygen, although lighter than the substrate, can also be observed using this technique. The polycrystalline carbon substrates were analyzed with the beam at normal incidence and the detector at an angle of $166^{\circ}$.

Retained deuterium was measured by means of the $D\left({ }^{3} \mathrm{He}, \mathrm{p}\right)$ a nuclear reaction with an incident beam energy of $700 \mathrm{keV}$. The detector was covered with $2 \mathrm{mt1}$ stainless steel to keep backscattered ${ }^{3} \mathrm{He}$ and alpha particles from interfering with the proten spectrum. Although hydrogen can be detected directly by RRA $\left[{ }^{1} H\left({ }^{19 F}, a \gamma\right)^{160}\right.$ or $\left.\left.{ }^{1} H\left({ }^{15}, Y\right)^{160}\right)\right]$, elastic recoil detection was used for this purpose in the present work. The incident beam was $2.3 \mathrm{MeV}{ }^{4} \mathrm{He}$ at $15^{\circ}$ from the sample surface and the scattered hydrogen was detected at an angle of $30^{\circ}$ from the incident direction. Both hydrogen and deuterium can be detected in this 
manner, and a typtcal spectrum is shown in Fig. 2. Because of the relatively short ranges assoctated with the low energy hydrogen and deuterfum implanted in the tokamak exposed samples, depth distributions of these isotopes were not useful.

If absolvite quantities of hydrogen or deuterfum present in exposed samples can be measured as a function of exposure, then the incident fluence and energy can be determined by comparison with appropriate trapping curves that show the quantity retained as a function of incident fluence and energy. 6 The results achieved with this method mere confirmed by measurements of damage to the single crystal silitcon samples as shown in Fig. 3. Such damage has been shown to be representative of the energy and fluence of the incident particles.? In the figure the lattice damage, as represented by the surface peak during axial channeling, is compared with curves of damage vs. Incident fluence and energy for monoenergetic deuterfum. The results for a position $4 \mathrm{~cm}$ outside the 11 miter radtus indicate a flux of $\sim 5 \times 10^{15} / \mathrm{cm}^{2}$ shot at an energy of $150 \mathrm{eV}$.

\section{RESULTS AND DISCUSSION}

\section{A. Impurfties}

The principal impurfties found in the plasma edge region of TEXTOR have been prevfously reported ${ }^{8}$ and were oxygen, fron, chromium, nickel, molybdenum, and traces of tungsten or tantalum. Carbon, which cannot be detected on Papyex substrates and can be only poorly resolved by RBS on silicon, may aiso be present in significant quantitfes, but was not included in these measurements. At $2 \mathrm{~cm}$ outside the limiter radtus average deposited fluxes were $\left(\mathrm{cm}^{-2} \mathrm{~s}^{-1}\right)$ : oxygen $=6 \times 10^{15}$, fron $=3 \times 10^{15}$, chromfum $=8 \times 10^{14}$, nickel $=3 \times 10^{14}$, and mol ybdenum $=2 \times 10^{13}$. The radial distributions of these impurities flowing along the ffeld lines in the electron drift direction are shown in Fig. 4. These 
results are for stlicon samples exposed to time-integrated discharges with the main limiters at $45 \mathrm{~cm}$. The metallic impurfties show a monotonic decrease with radfus that is less than exponential. The e-folding distance observed for the metals is $\sim 2.5 \mathrm{~cm}$. The relatfvely sharper decrease at $r=48-49 \mathrm{~cm}$ is due to the effects of the inner limiter and the secondary limiters on the ICRH antenna which are located at this. radtus. The behavfor of the depostted oxygen flux is different from that of the metals. The oxygen fiux decays more siowly with radius, indicating that the source or mechanism of introduction into the plasma for oxygen is different than for the metals.

Possible saturation effects in the deposition of impurities were investigated by exposing samples to varfous numbers of discharges. The results are shown in Flg. 5. Here the quantfties of stainless steel, molybdenum, and.oxygen retained or, the probe at three different radif are plotted against the number of discharges to wich the silicon samples were exposed. It is apparent that saturation effects for oxygen occur after the first discharge, while for the metals the deposition rate is essentially constant for six discharges. A comparison of this data with time-resolved data for fluences of less than one discharge demonstrates that the deposition rate for oxygen is approximately constant up to the one discharge level $\left(1.5 \times 10^{16} \mathrm{~cm}^{-2}\right)$. This linearity is important in relating measurements of accumulated impurtties to the incldent flux. Thus the measured results for metals are valid for exposures of up to stx discharges, but results for oxygen may be suspect beyond one discharge.

The time dependence of the impurity fluxes was measured for $2.5 \mathrm{~s}$ TEXTOR discharges using rotating probe techniques. The results at a radius of $49.7 \mathrm{~cm}$ are given in Fig. 6. The time resolution of the data is $\pm 0.14 \mathrm{~s}$. The inftial peak near time zero has been generally observed on other machines 1 and is 
ascribed to positional instability during the startup pirase. Such instability also appears to be the explanation for the peaking in these TEXTOR discharges, since the measured horizontal position of the plasma was very unsteady at that time. The peak that is especially prominent in the transition metal flux and is centered at one second into the discharge, however, cannot be readily explained. Plasma position, density and temperature are all nearly constant during this part of the discharge and no other perturbations to the plasma at this time have been observed.

\section{B. Hydrogen Isotopes}

Nuclear reaction analysis was used to determine the amount of deuterfum trapped in samples exposed to different numbers of discharges. 9 The data were then compared with trapping curves (see Sect. II) to estimate incident flux and energy. A flux of $1-1.5 \times 10^{16} / \mathrm{cm}^{2}$ discharge with a Maxwellian energy distribution of $\sim 100 \mathrm{eV}$ was found at $5 \mathrm{~cm}$ outside tl. " limiter radius.

The use of ERD to determine both hydrogen and deuterium fluxes is illustrated in Fig. 7. In this case deuterium gas was puffed into a hydrogen plasma as indicated in the figure. Both hydrogen and deuterium were monitored using the time-resolved rotating collection probe at $3.6 \mathrm{~cm}$ behind the limiter. The puffed deuterium is detected immediately on the collection probe, but the amount decays gradualily when the gas inlet is closed. The amount of deuterium then rises sharply as the discharge ends. In this case the discharge ended in less than two seconds with a minor disruption. The final increase in both $H$ and D fluxes is presumab?y due to the increased contact with the wall and limiters during this disruption. 


\section{Other Probe Measurements}

A number of different surface probe systems have been used on TEXTOR for plasma edge studies. Each of them emphasized a different aspect of the plasmawall problem, and each of them employed a different investigative technique. Two of them operated during the tfme frame of the present measurements and one of them relied on accelerator based analysis techniques. In this section the characteristics of these systems will be briefly described and results pertinent to the present work will be discussed.

Two surface analysis stations using Auger electron spectroscopy (AES) for sample analysis were installed on TEXTOR for the evaluation of wall conditioning procedures.10.11 Samples of the first wall material (Inconel 625) were exposed at the wall position to radio frequency supported glow discharge (RG) and electron cyclotron resonance (ECR) cleaning and then analyzed by AES. In this way the effects of the cleaning on the walls could be determined. Wall conditfon was then correlated with plasma performance. These probes were not used to characterfze the scrapeoff layer during tokamak discharges.

A material manipulator has been installed on TEXTOR by a collaborative effort from Switzerland.12 Thts mantpulator can install and remove samples from a large number of different locations in the liner. The device is meant for long term exposure of samples, such as the testing of first wall materials and coatings, and is not used for plasma edge characterfzation.

An interesting probe has been installed by members of the Instftut fur Chemie 1 at KFA, Julfch.13 This probe was designed primartly for measuring hydrogen isotope fluxes in the edge during tokamak discharges. It uses conventional deposition probe collection of particles on graphite strips and can operate in the time-resolved mode. Analys is of the retained fluence, however, is done in 
situ by thermal desorption and mass spectrometric detection. Hydrogen fluxes were measured for standard discharges simflar to those reported here. Fluxes of $10^{16} / \mathrm{cm}^{2}$ shot with a Maxwell1an energy of $100 \mathrm{eV}$ were found at $4 \mathrm{~cm}$ behind the 1 imfter radius in the electron drift direction. These are comparable to the results reported in the present work. An attempt to use this thermal desorption probe to measure heavier impurities has so far been unsuccessful.

The work most comparable to that reported here was carried out on the "Stockholm probe" which was located $140^{\circ}$ toroldally in the lon drift direction from our probe. This probe used rotating Papyex collectors in cylindrical geometry and RBS analysis to determine impurity fiuxes in the edge. For exposures in the lon drift direction comparable fluxes of the transition metals (5.5 $x 10^{15} \mathrm{~cm}^{-2} \mathrm{~s}^{-1}$ ) and somewhat higher fluxes of oxygen ( $x 2$ to 3 ) were observed at comparable radif. ${ }^{14}$ A substantial difference in e-folding lengths was observed with a value of $1.0 \mathrm{~cm}$ being measured at their torotdal location. Since different flux tubes are being sampled by the two probes, it is difficult to determine whether these differences are the direct result of proximity to the 1 imiter.

\section{CONCLUSION}

Accelerator based analysis techniques and passive deposition probe exposures were used to characterize the plasma edge rection of TEXTOR. Using RBS, the spectes and quantities of impurities in the scrapeoff layer were determined as functions of radial position and time for standard ohmic discharges. Retained quantities of hydrogen tsotopes were measured by NRA and ERD. Trapping curves were then used to determine incident fluxes and energies from these values. 
$-10-$

Comparisons with other probe measurements show modest agreement with regard to impurity fluxes and hydrogen fluxes and energies in the edge, but indicate that toroidal variations of 2 to 3 may be expected in some cases. In summary, the international collaboratforis on TEXTOR in the area of plasma-materials interactions hive fostered this and a number of other investigations that together have led to an improved understanding of conditions in the plasma edge. 


\section{REFERENCES}

1. For a recent review of deposition probe techniques see: R. A. Zuhr, J. B. Roberto, and B. R. Appleton, Nucl. Sc1. Appl. 1, 617 (1983).

2. For a review of plasma-wall interactions see: G. M. McCracken and P. E. Stott, Nucl. Fusion 19, 889 (1979).

3. Ion Beam Handbook for Materials Analysis, ed. by J. W. Mayer and E. Rinint, Academic Press, New York, 1977.

4. B. L. Doyle and P.S. Peercy, Appl. Phys. Lett. 34, 811 (1979).

5. Channeling, ed. by D. V. Morgan, John Wiley and Sons, New York, 1973.

6. S. A. Cohen and G. M. McCracken, J. Mucl. Mater. 84, 157 (1979).

7. S. P. Withrow, R. A. Zuhr, and J. Roth, J. Vac. Sct. Technol. 20 (4), 1323 (1982).

8. R. A. Zuhr, J. Vac. Sct. Technol., to be published.

9. R. A. Zuhr, J. Vac. Sci. Technol. A2, 686 (1984).

10. R. E. Clausing, F. Waelbroeck, J. Winter, P. Wienhold, L. Könen, and N. Noda, J. Nuc1. Mater. 121,249 (1984).

11. R. E. Clausing, K. G. Tschersich, H. P. Fleischhauer, L. Heatherly, F. Waelbroeck, J. Winter, P. Wienhold, Y. Sakamoto, S. Ishit, and K. Yano, J. Nucl. Mater. 122/123, 1145 (1984).

12. This collaboration is represented by S. Verprek, University of Zurfich, Zurtch, Switzerland.

13. V. Philipps, M. Erdweg, and E. Vietzke, Proceedings of the 6th Int. Conf. on Plasma Surface Interactions in Controlled Fusion Devices, Nagoya, May 1984, to be published in J. Mucl. Mater.

14. B. Emmoth, M. Braun, H. E. Satherblom, P. Wienhold, J. Winter, and F. Waelbroeck, Proceedings of the 6th Int. Conf. on Plasma Surface Interactions in Controlled Fusion Devices, Nagoya, May 1984, to be published in J. Nucl. Mater. 
FIGURE CAPTIONS

Fig, 1 Exposure geometry for the time-resolved deposition probe showing silicon collection samples mounted on the rotating drum.

Fig. 2 Elastic recoll detection spectrum fllustrating the separation of $H$ and $D$ for the indicated geometry.

Fig. 3 Damage (surface peak yield) for single crystal silicon (100) as a function of dose and energy for monoenergetic incident deuterium. The s are measured damage for samples exposed $4 \mathrm{~cm}$ outside the limiter radius in TEXTOR.

Fig. 4 Radial distribution of FeCrNi $(O), 0(\square)$, and Mo $(\Delta)$ fluxes along the field lines in the electron drift.direction during ohmic hydrogen discharges.

Fig. 5 Saturation effects observed in plots of retained impurities versus number of hydrogen discharges at radit of $47.6(O), 49.5(\square)$ and $51.4(\Delta) \mathrm{cm}$.

Fig. 6 Time-resolved fluxes of FeC̣rNi $(O), 0(\square)$ and Mo $(\Delta)$ for ohmic hydrogen discharges. Time resolution is $\pm 0.14 \mathrm{~s}$.

Fig. 7 Retained hydrogen ( $\square$ ) and deuterium ( $O$ ) fluxes versus time for deuterium puffing into hydrogen discharges at $3.6 \mathrm{~cm}$ outside the 1 imiter radius. 


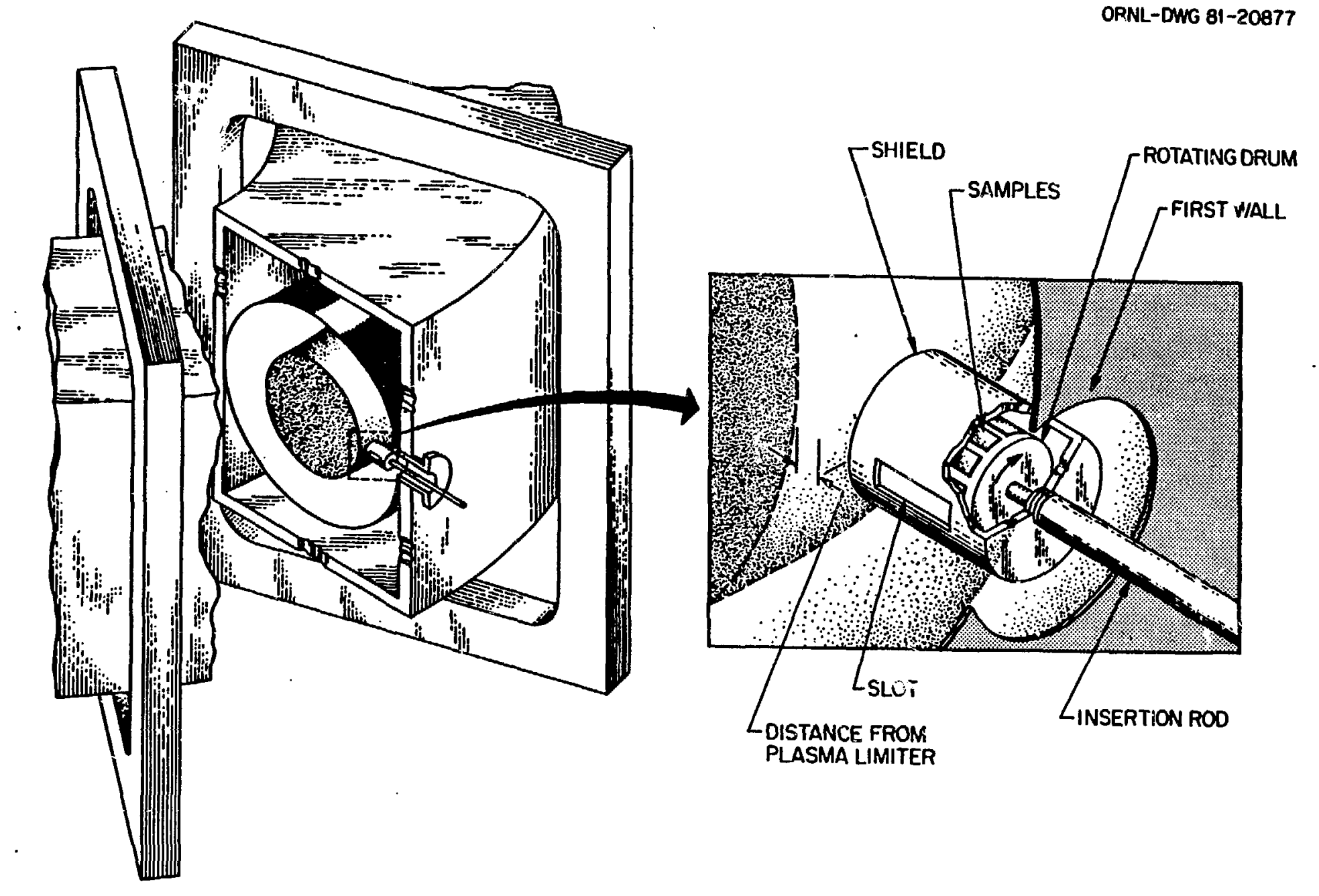

Ftg. 1 


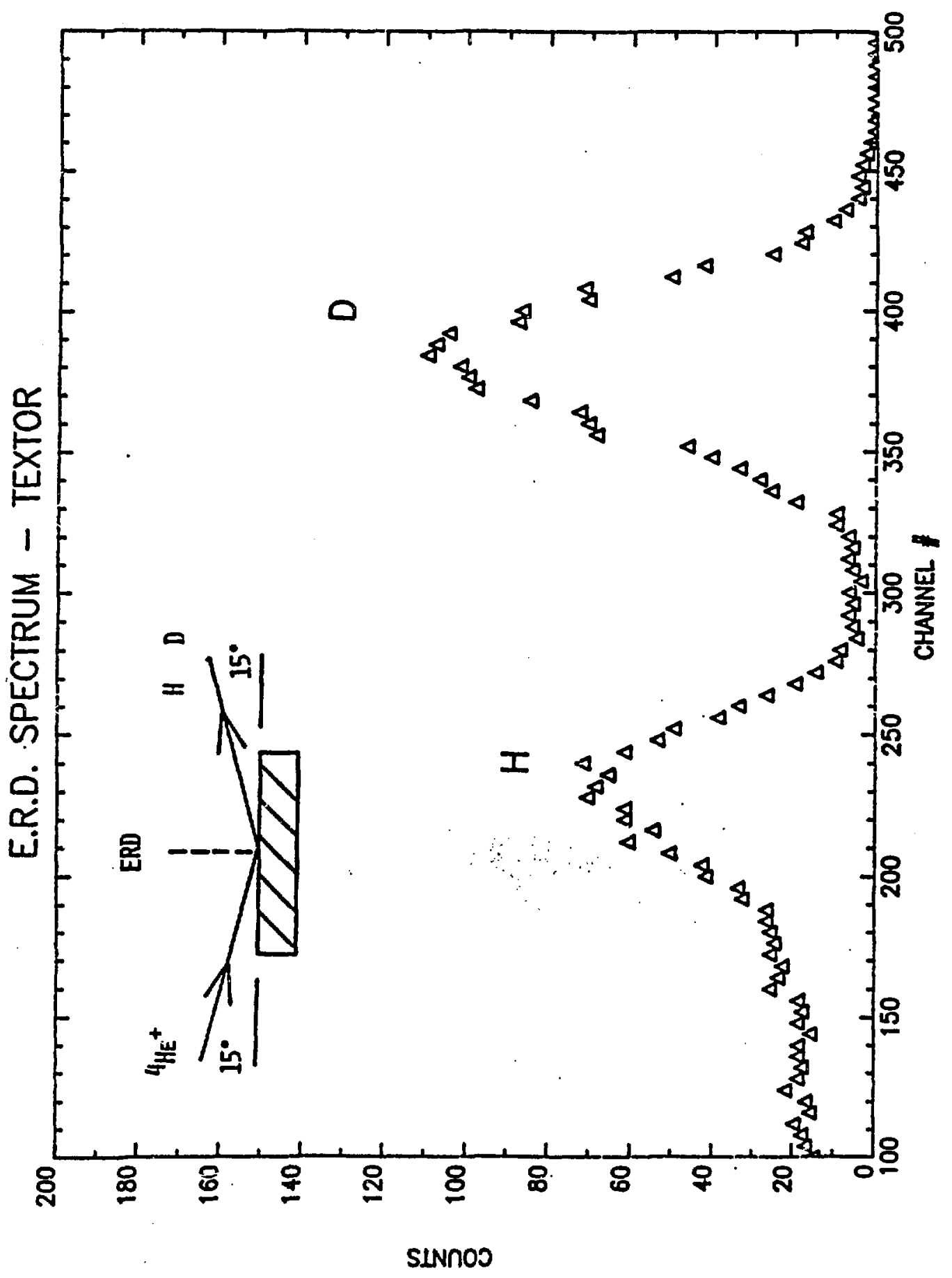

$\infty$
$\dot{0}$ 


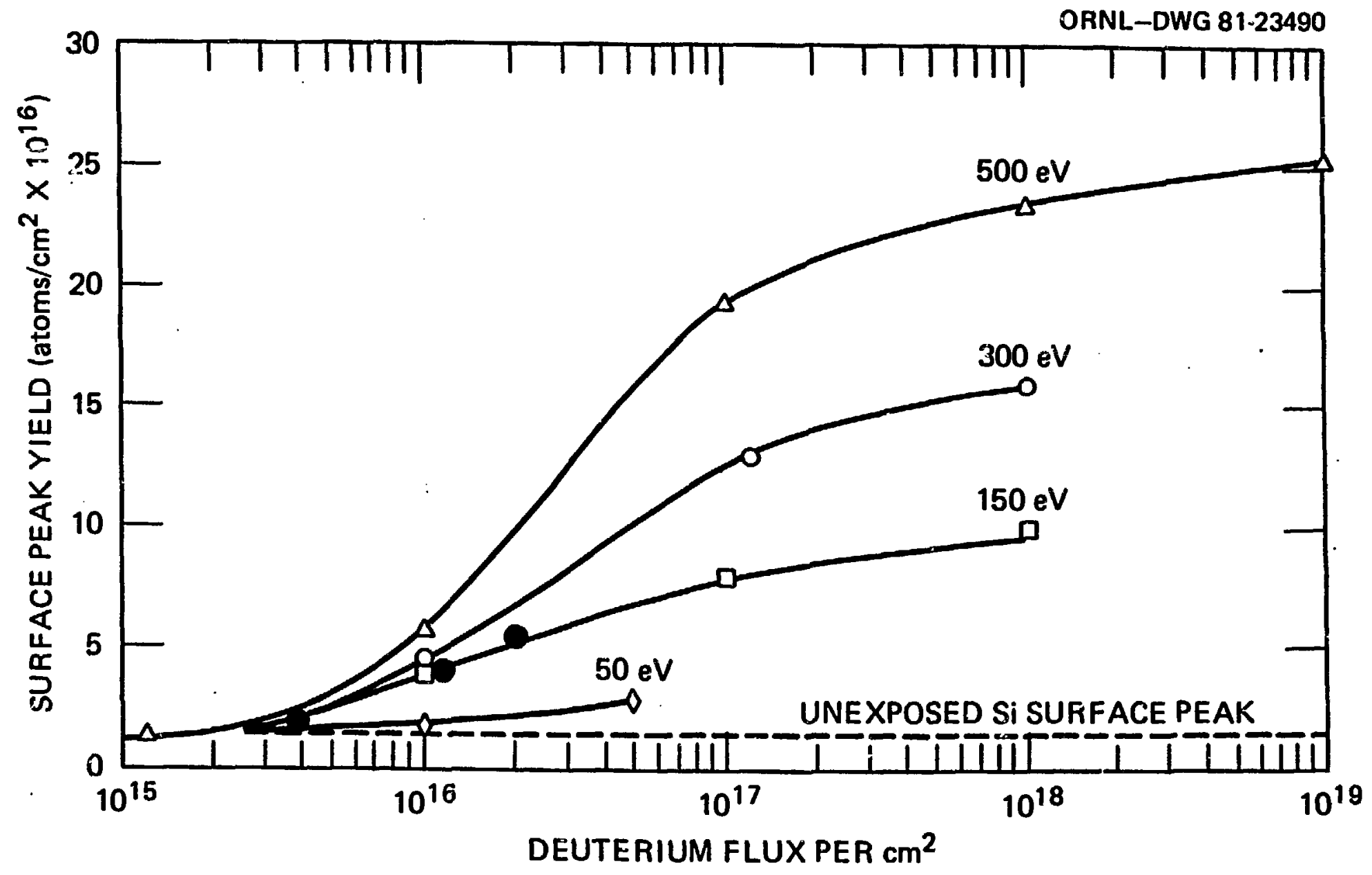

Fig. 3 


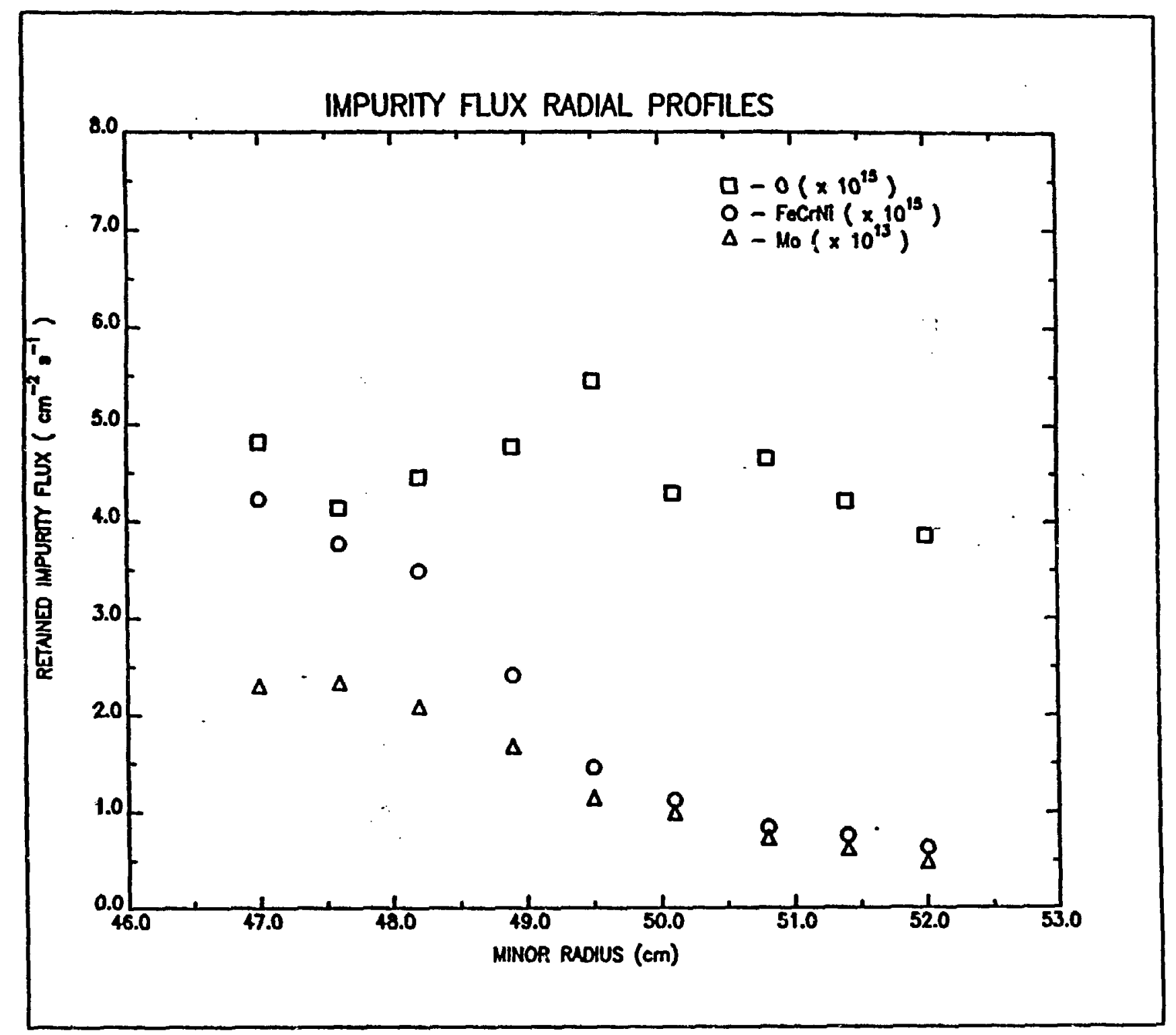

F19. 4 


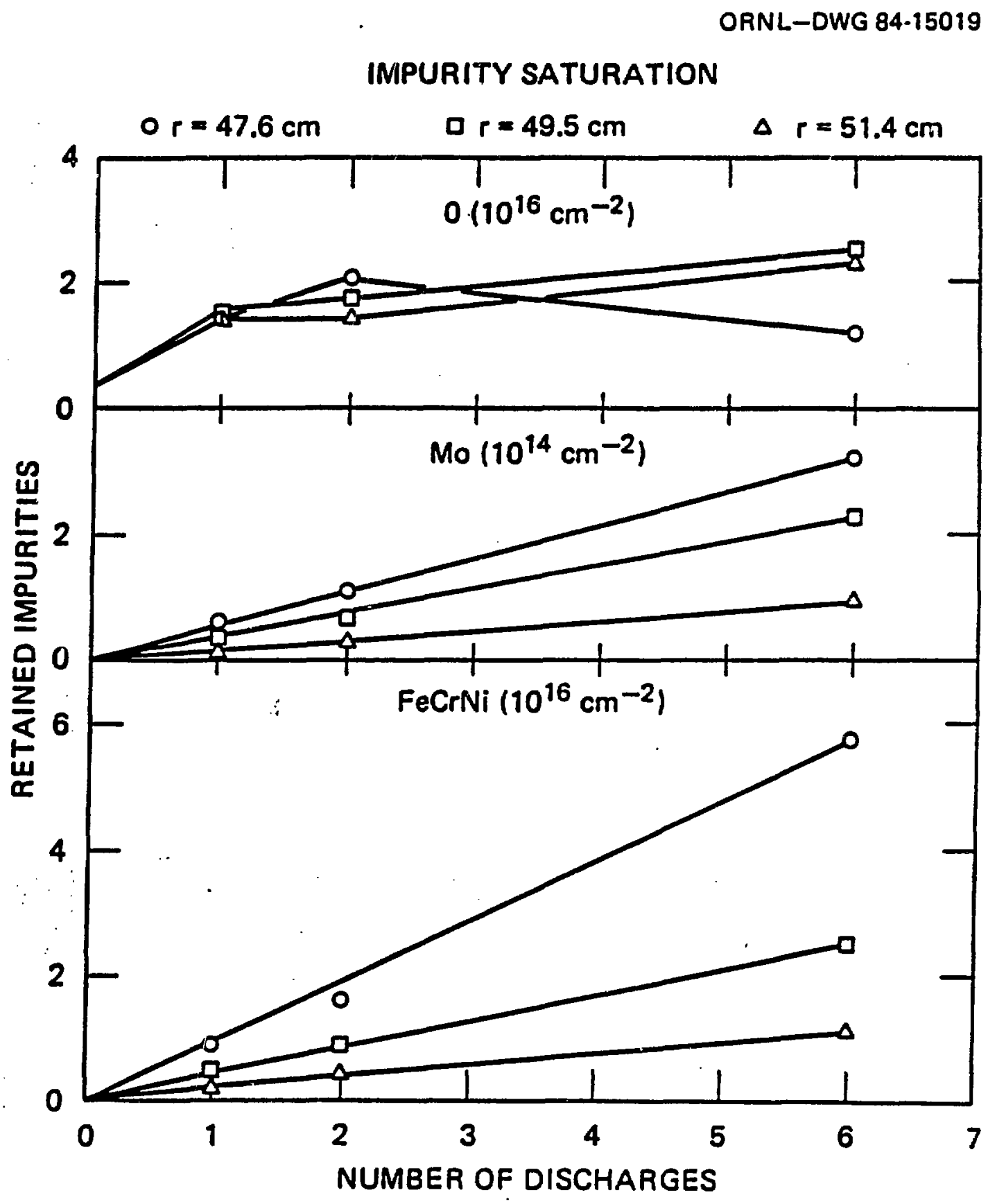

Fig. 5 
ORNL-DWG 84-15018

TIME RESOLVED IMPURITY FLUX

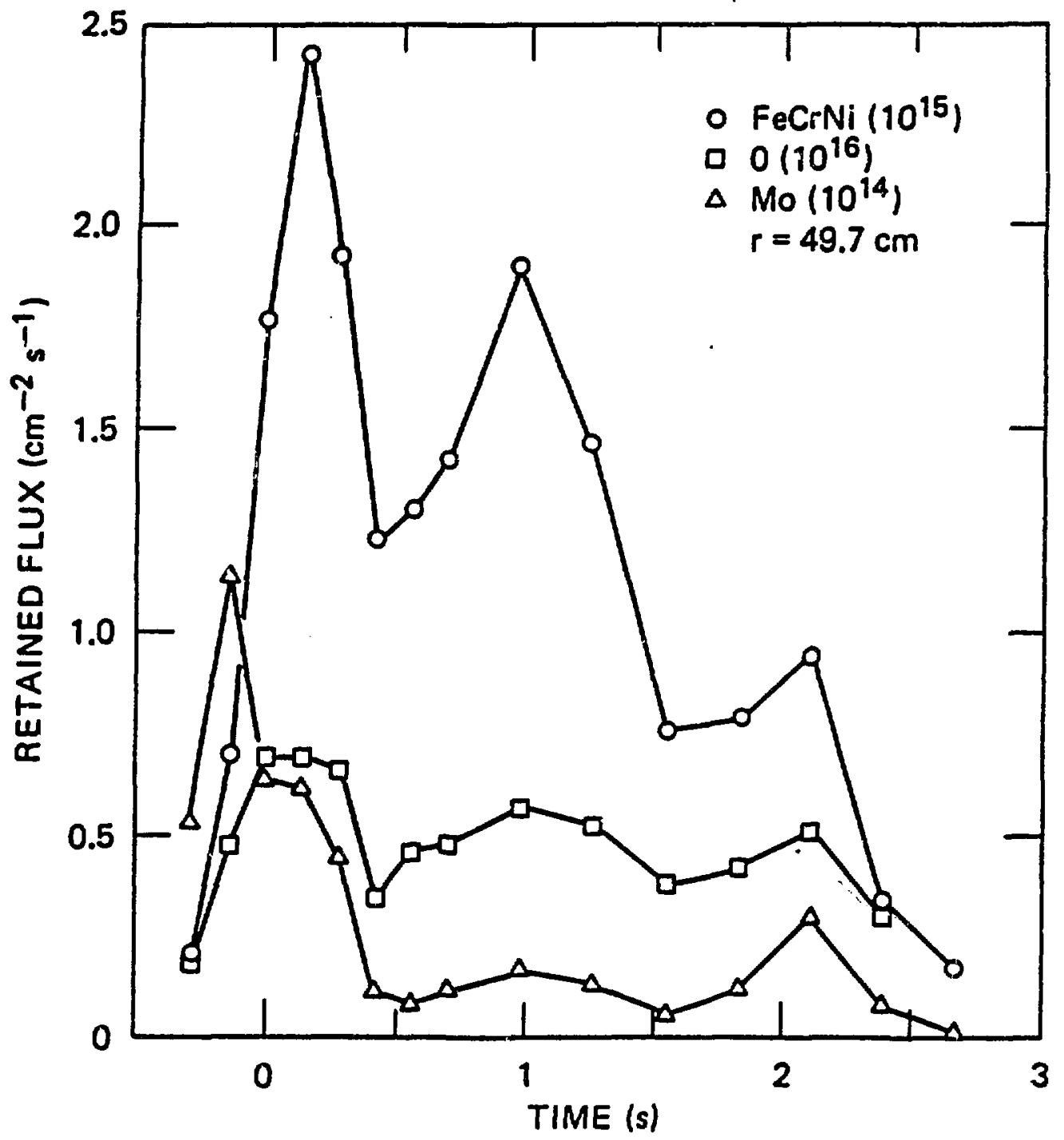

Fig. 6 


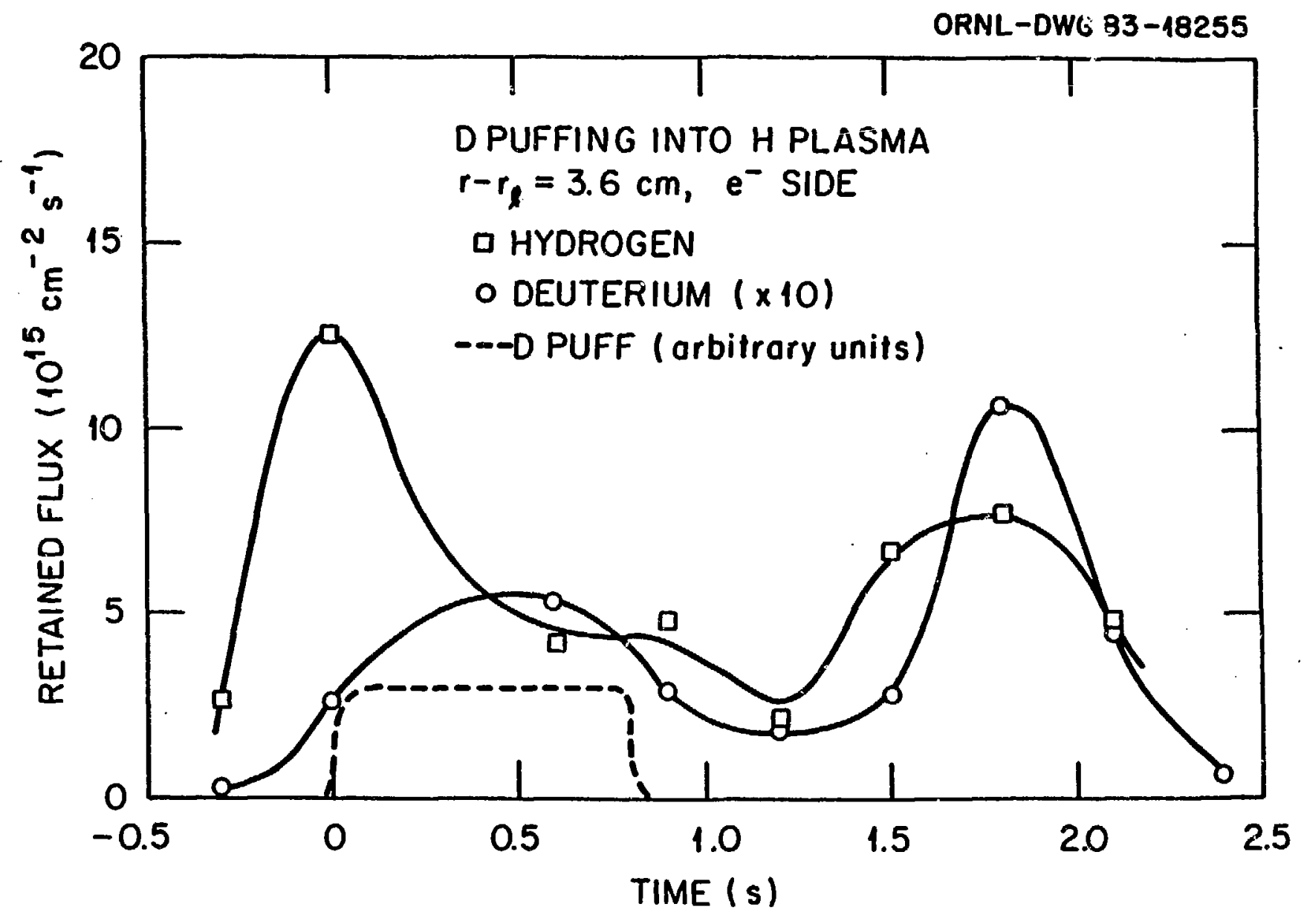

Fig. 7 